\title{
EFFECT OF VARIABLE PRESSURE AND TAR CONTENT ON THE BRIQUETTING OF ALABAMA GRAPHITE.'
}

By R. T. Stuli, and H. G. Schurecht.

The Ceylon graphite occurs in comparatively large lumps and when ground and screened produces a material having a granular

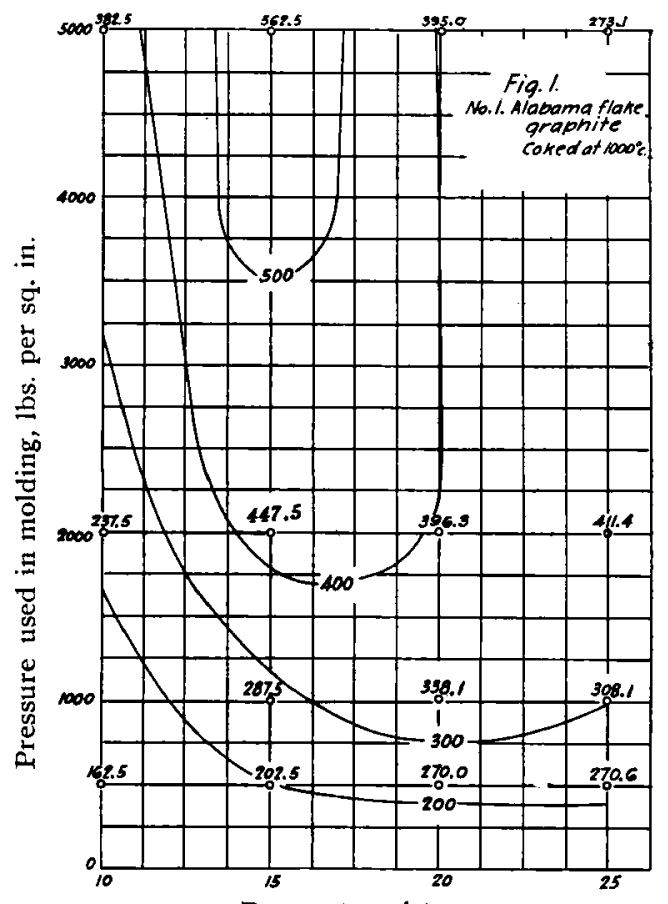

Per cent coal tar.

Effect of tar and pressure on compressive strength of coked Alabama graphite.

or splintery structure. On account of the comparatively large size of the lumps, it can be ground to almost any size of meshing desired. On the other hand, the Alabama graphite when pre-

${ }^{1}$ By permission of the Director, U.S. Bureau of Mines. 
pared for the market occurs in a thin flat plate-like form seldom coarser than a 20 -mesh size.

The argument which has been advanced by crucible-makersto support their contention that the Ceylon graphite is superior to the flake form for the manufacture of crucibles-is that the granular and splintery graphite grains produce a stronger and

The effect of tar and pressure on the porosity of coked graphite.

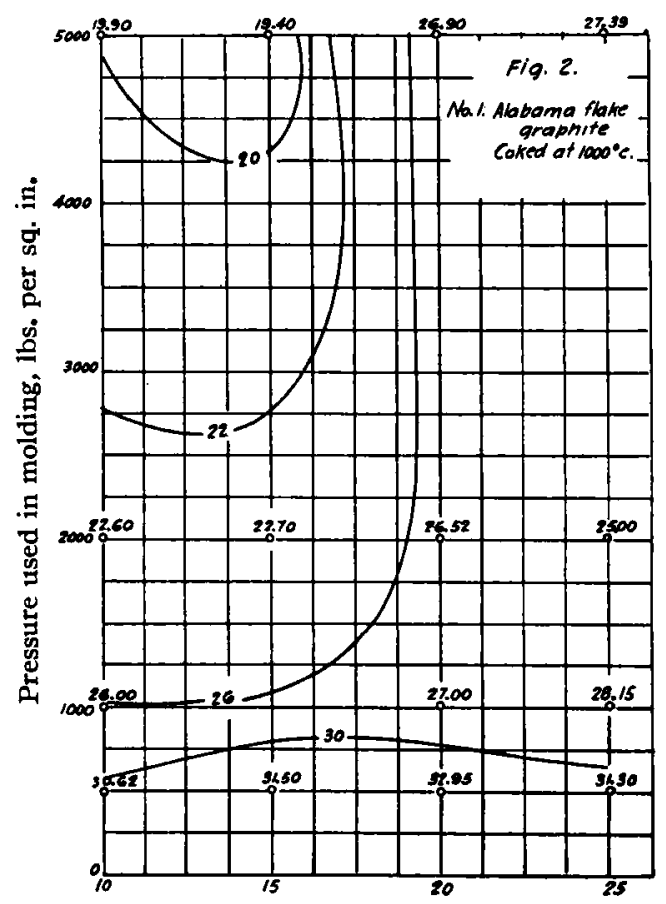

Per cent coal tar.

more durable crucible, due to the interlocking or "tying in" of the granules and splinters with the bond clay. On the other hand, the structure in the flake graphite body appears to be that of over-lapping plates which, it is claimed by a minority of domestic crucible makers, when bound together produce a stronger body than the granular form.

It was therefore suggested that if the Alabama flake graphite 
could be modified in such a manner as to produce a granular form, larger than 20-mesh in size, the crucible making properties of graphite so prepared could be compared with those of the flake and the Ceylon, thereby throwing some light upon the question. Experiments were made to convert the Alabama flake graphite to the granular form by briquetting the graphite with

Effect of tar and pressure on the density of coked Alabama graphite.

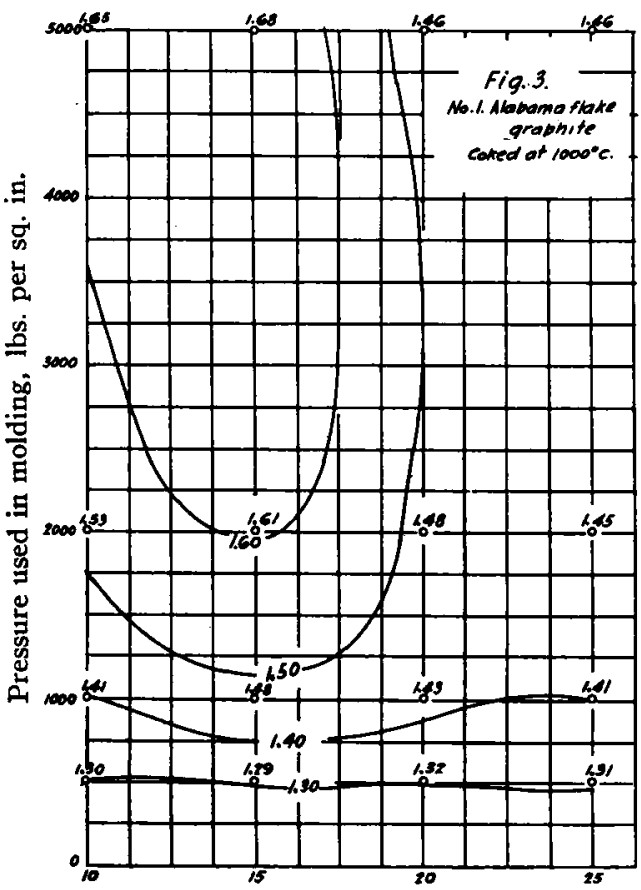

Per cent coal tar.

tar, coking, crushing and screening. In order to produce a high degree of "compactness" and to approximate the Ceylon grain as closely as possible, a study of the effects of different briquetting pressures and different per cents of tar binder was undertaken.

Two series were made. In Series I the Alabama flake graphite, screened between 20- and roo-mesh, was mixed with 10, I5, 20 and 25 percent coal tar (by weight), briquetted at different pres. 
sures up to 5000 pounds per square inch on an Olsen compression testing machine, and coked rapidly at $1000^{\circ} \mathrm{C}$.

Series 2 was a duplicate of Series I except that a mixture of three parts flake graphite and one part graphite dust passing the roo-mesh screen was used.

In order to determine the best pressure and per cent of tar to The effect of tar and pressure on the bulkiness of Alabama coked graphite.

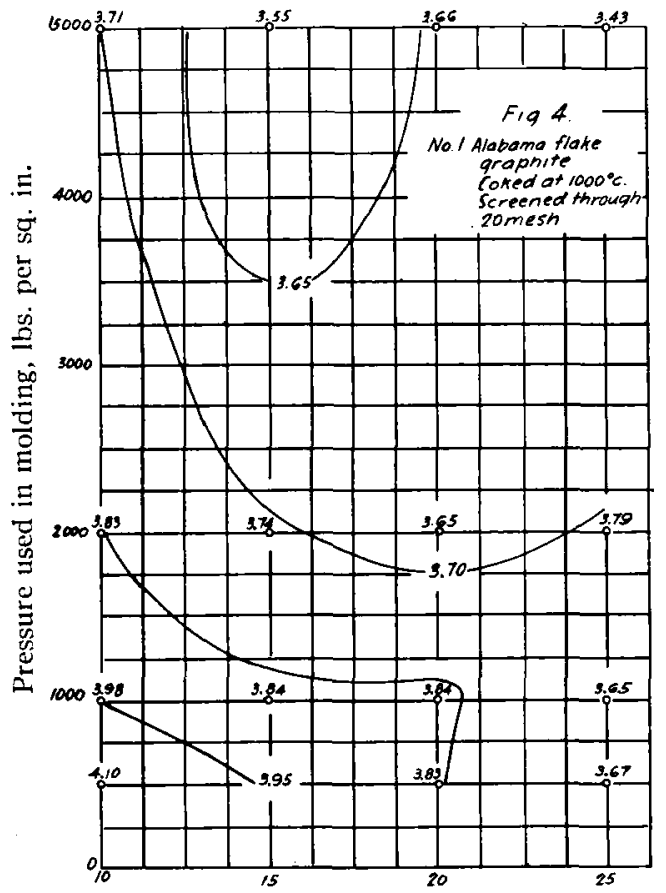

Per cent coal tar.

employ, the crushing strength, porosity, apparent density and bulkiness measurements were made on the coked samples.

The compressive strength tests were made on five check trials for each different set of conditions on cylinders $2^{1} / 2^{\prime \prime}$ in diameter and 3 " high.

The porosity and apparent density determinations were made by the kerosene oil-immersion method on three check trials. 
Bulkiness measurements were made by crushing the coked briquettes and screening between 20 and 100 mesh in order to secure results comparable with the tests on the 20-mesh flake graphite. Eighty grams of the prepared material with about I $40 \mathrm{cc}$. of distilled water were placed in a graduated cylinder and the graphite allowed to settle for 24 hours, when the height

Effect of tar and pressure on compression strength of coked Ala. graphite.

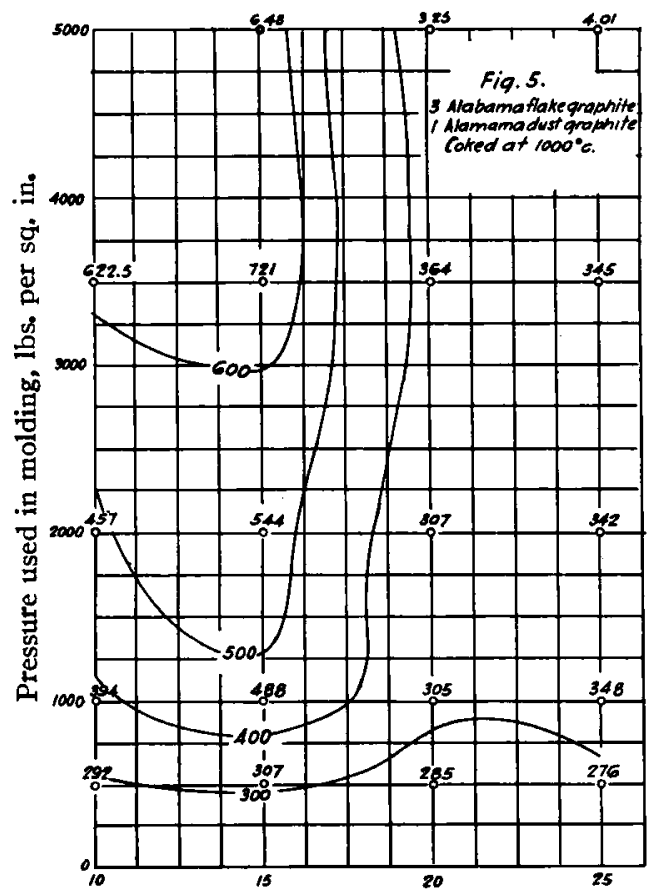

Per cent coal tar.

of the graphite in cubic centimeters was noted. The bulkiness was expressed in terms of the ratio of the number of cubic centimeters of graphite observed, divided by its true volume. For comparison, bulkiness measurements were also made on Ceylon, Canadian, and No. I Alabama flake graphites. All were screened between 20 and 100 mesh.

The comparative bulkiness was found to be as follows: 


\begin{tabular}{|c|c|}
\hline & $\begin{array}{c}\text { Bulkiness } \\
\text { factor. }\end{array}$ \\
\hline Ceylon graphite. & 2.36 \\
\hline Canadian graphite. & $3.5 \mathrm{I}$ \\
\hline Alabama coked. . & 3.54 \\
\hline Alabama flake. . & 3.90 \\
\hline
\end{tabular}

In order to show graphically the results obtained, crushing strength, porosity, apparent density and bulkiness lines were Effect of tar and pressure on porosity of coked Ala. graphite.

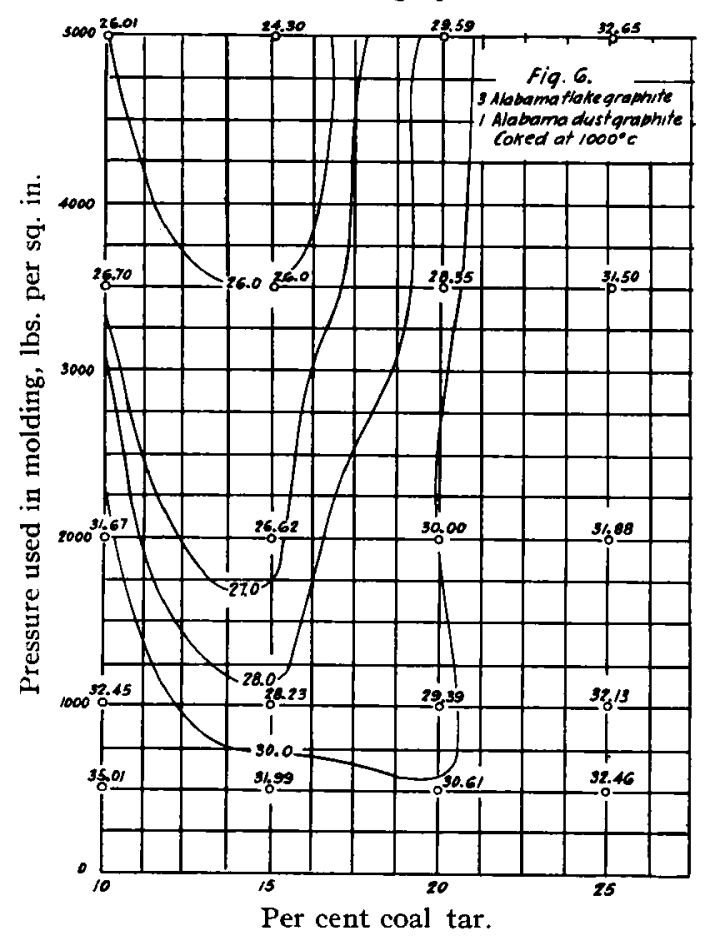

plotted. The pounds per square inch under which the briquettes were compressed are spaced on the ordinates and the percentages of tar spaced on the abscissae. Figs. I, 23 and 4 show the results for Series I, and Figs. 5, 6, 7 and 8 for Series 2.

As anticipated, the curves show that highest crushing strength, lowest porosity, highest density and lowest bulkiness occur 
with highest pressures of briquetting in both series. In Series I for the flake graphite, the curves show that about I 4 to I 5 per cent tar gives the maximum crushing strength, minimum porosity, maximum density and minimum bulkiness for the highest briquetting pressures, and, in general, as the briquetting pressure decreases the amount of tar must increase up to a limit of ap-

Effect of tar and pressure on the density of coked Ala. graphite.

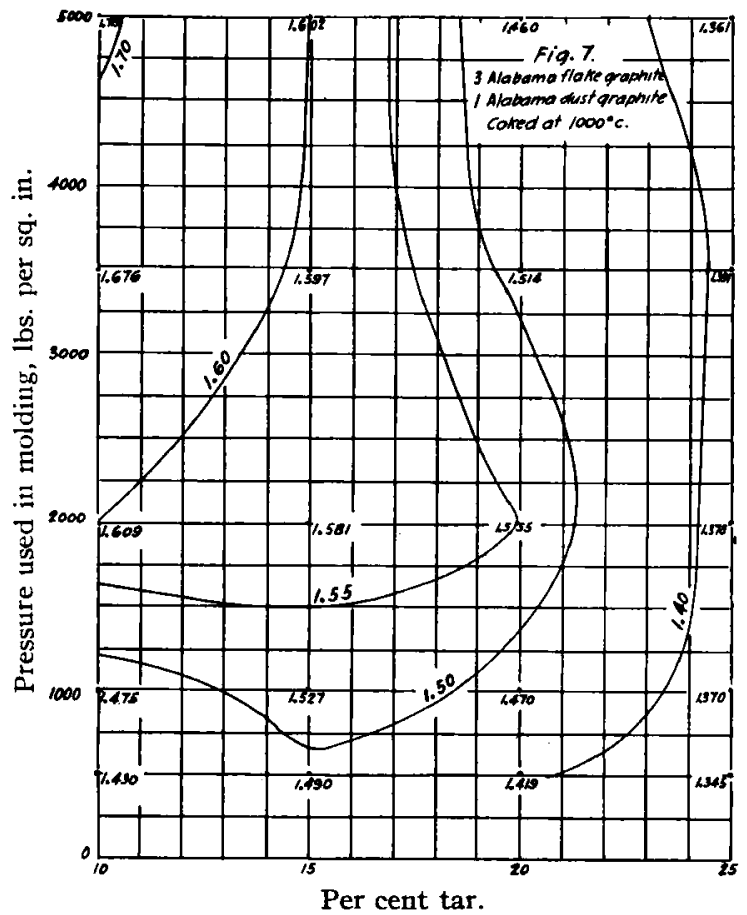

proximately 20 per cent for the lowest briquetting pressures in order to give the most desirable results.

With the mixture of flake and dust graphite, Series 2, maximum crushing strength, minimum porosity, and minimum bulkiness for each briquetting pressure occur with is per cent tar binder. Maximum density occurs with Io per cent tar at 5000 pounds briquetting pressure and with 15 per cent tar at 500 pounds pressure. 
High compressive strength, high density, low porosity and low bulkiness are the properties most desired. These were obtained with the highest briquetting pressure employed (5000 pounds per square inch) and for any definite addition of tar, were most nearly attained with 15 per cent tar binder.

A comparison of Series $I$ and 2 at 5000 pounds briquetting

Effect of tar and pressure on the bulkiness of coked Ala. graphite.

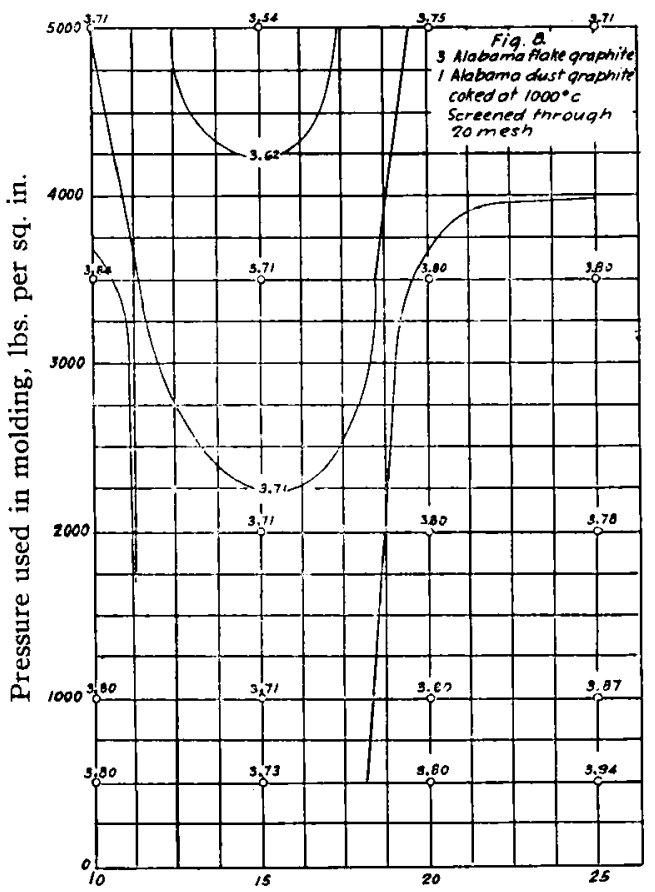

Per cent coal tar.

pressure and is per cent tar content shows that the mixture of flake and dust gave higher compressive strength and higher porosity than the flake graphite and approximately the same density and bulkiness as the flake graphite.

Two hundred pounds of the coked graphite was prepared for making crucibles. This consisted of three parts No. I Alabama flake of No. 20-mesh size and one part Ioo-mesh graphite dust. 
Fifteen per cent of coal tar by weight was selected as the binder and the briquettes were formed under a pressure of 5000 pounds per square inch. After coking at $1000^{\circ} \mathrm{C}$ the briquettes were crushed and screened between 16- and roo-mesh sieves.

The Alabama flake graphite has a decidedly greasy feel, while the "slippery" feeling of the Ceylon is much less. As compared to the flake and Ceylon, the coked grain appears harsh and the greasy feel is almost lacking. As compared to the Ceylon grain, the coked grain is short and "chunky," whereas the Ceylon grain is longer and narrower.

Two series of crucibles were made, one containing variable amounts of Ceylon and No. I Alabama flake graphite, and the other different per cents of Ceylon and coked Alabama graphite.

The crucibles containing all Alabama graphite molded with difficulty. Owing to its slipperiness, the mixture seemed to stick to the jigger tool and slide rather than pack against the mold. It did not seem to weld readily and laminated badly and when removed from the mold showed numerous welding seams. The Ceylon graphite crucibles molded much better than the flake mixture but showed a slight tendency to laminate and an occasional welding seam. The coked graphite molded perfectly, showed no tendency to laminate and no welding seams. The crucibles came from the molds apparently flawless as far as molding properties were concerned.

The crucibles were tested in a large brass foundry on two different grades of brass. Contrary to predictions, the all Alabama flake crucibles gave better service than the coked graphite crucibles, and both the coked and flake graphite crucibles gave better service than the Ceylon crucibles. The results are interesting though not conclusive-since only four crucibles of each mix were tested. ${ }^{1}$

Bureau OF MINES,

Mining Experiment Station,

Columbus, Ohro.

${ }^{1}$ For more complete data regarding tests of these crucibles see "Behavior Under Brass Foundry Practice of Crucibles Containing Ceylon, Canadian and Alabama Graphites." J. Am. Ceram. Soc., 2, 208 (March 1919). 